\title{
A genetic risk assessment for prostate cancer influences patients' risk perception and use of repeat PSA testing: a cross-sectional study in Danish general practice
}

\author{
Jacob Fredsøe ${ }^{1,2 *}$, Pia Kirkegaard ${ }^{3}$, Adrian Edwards ${ }^{4}$, Peter Vedsted $^{5}$, \\ Karina Dalsgaard Sørensen ${ }^{1,2}$, Flemming Bro ${ }^{6}$
}

${ }^{1}$ Department of Molecular Medicine, Aarhus University Hospital, Aarhus, Denmark; ${ }^{2}$ Department of Clinical Medicine, Aarhus University, Aarhus, Denmark; ${ }^{3}$ Department of Public Health Programs, Randers Regional Hospital, Randers, Denmark; ${ }^{4}$ Division of Population Medicine, School of Medicine, Cardiff University, Cardiff, UK; ${ }^{5}$ Department of Public Health, Research Centre for Cancer Diagnosis in Primary Care, Aarhus University, Aarhus, Denmark; ${ }^{6}$ Department of Public Health, Research Unit for General Practice Aarhus University, Aarhus, Denmark

*For correspondence: jcf@clin. au.dk

Competing interest: The authors declare that no competing interests exist.

Received: 07 January 2020 Accepted: 10 January 2020 Published: 27 May 2020

(C)This article is Open Access: CC BY license (https://creativecommons.org/licenses/by/4.0/)

Author Keywords: prostatespecific antigen, prostatic neoplasms, risk assessment, general practice, surveys and questionnaires, genetic testing

Copyright (C) 2020, The Authors;

DOI:10.3399/

bjgpopen20X101039

\begin{abstract}
Background: Prostate cancer (PC) is the most common cancer among men in the western world. Genetic lifetime risk assessment could alleviate controversies about prostate specific antigen (PSA) testing for early diagnosis.
\end{abstract}

Aim: To determine how men interpret information about their lifetime risk for PC and how this can affect their choice of having a repeated PSA test.

Design \& setting: A genetic test was offered for assessment of individual PC lifetime risk in general practices in Denmark, with the purpose of promoting appropriate use of PSA testing.

Method: Participants had a genetic lifetime risk assessment for PC diagnosis (either high or normal risk). A month after receiving the result, participants answered a questionnaire about their perceived risk of getting or dying from PC compared with other men, as well as their intentions for repeated PSA testing.

Results: Nearly half (44.7\%) of 555 participants who received the genetic risk assessment were not aware they had a genetic test. Nevertheless, compared with men with a normal genetic risk, those with high genetic risk reported higher perceived risk for PC (mean difference of 0.74 [95\% confidence interval $\{\mathrm{Cl}\}=0.56$ to 0.96 ] on a 5-point scale), higher perceived risk of dying from PC (mean difference of 0.48 [95\% Cl $=0.29$ to 0.66 ] on a 5-point scale), and increased intention for repeated PSA testing (mean difference of $0.48[95 \% \mathrm{Cl}=0.30$ to 0.65$]$ on a 4-point scale).

Conclusion: Despite low awareness and/or understanding of the test result, a high genetic risk for PC made participants more aware of their risk, and it increased their intention and probability for repeated PSA testing. 


\section{How this fits in}

Most guidelines advise against population-based screening using the PSA test. Here, a genetic test was offered for assessment of individual PC lifetime risk in Danish general practice, with the purpose of promoting appropriate use of PSA testing. A month after receiving the result, participants answered a questionnaire about their perceived risk of getting or dying from $\mathrm{PC}$, as well as their intentions for repeated PSA testing. Despite low awareness and/or understanding of the test result, having a high genetic risk for PC made participants more aware of their risk, and it increased their intention and probability for repeated PSA testing.

\section{Introduction}

PC is the most common cancer among men in Europe, with approximately 190000 new cases and about 80000 deaths every year. ${ }^{1-4}$ A commonly used method for early detection of PC is the PSA test, although this method has limited accuracy. ${ }^{5,6}$ This results in failure to detect genuinely aggressive disease at an early stage, as well as overdiagnosis and overtreatment of indolent cancers that would not give rise to symptoms in the patient's normal lifespan if left undetected. Therefore, most guidelines advise against population-based screening using the PSA test. ${ }^{7,8}$ Still, the PSA test is frequently requested by some men and opportunistically offered by GPs, typically in relation to lower urinary tract symptoms (LUTS) or regular health checks. ${ }^{9}$

Risk stratification has been proposed as a strategy to improve the benefit-to-harm ratio of (opportunistic) PSA screening by targeting PSA testing to those men most likely to benefit. ${ }^{10}$ Genetic markers are candidates to provide such risk assessment for PC, and advances in genomewide association studies have so far identified around 200 genetic variants associated with higher PC lifetime risk, termed single nucleotide polymorphisms (SNPs). ${ }^{11-14}$ Furthermore, retrospective studies comparing non-genetic risk prediction models versus risk prediction models, including genetic markers (SNPs), have reported significantly higher specificity for the genetic models. ${ }^{15-17}$ From a patient perspective, knowledge of one's lifetime PC risk could enhance accuracy of perceived susceptibility ${ }^{18,19}$ and aid in shared decision-making about PSA testing. ${ }^{20}$

To the authors' knowledge, no previous clinical studies have investigated if a genetic PC risk assessment can be utilised as a tool for optimising the use of PSA testing in a general practice setting. An intervention was previously developed ${ }^{21,22}$ in which a genetic lifetime risk assessment for PC was offered to patients who had a PSA test at their general practice. The aim was to enhance appropriate PSA testing by: (a) reducing the number of unnecessary PSA tests (opportunistic screening) in men with a normal lifetime risk; and (b) promoting targeted PSA screening of high-risk men ( $\geq 30 \%$ lifetime risk) to ensure early detection. The result of a genetic PC risk assessment could then support decisions where both patient and GP had additional information about the future risk of getting a PC diagnosis.

The aim of this study was to explore whether patients were aware of the genetic test, and how information about lifetime risk influenced their perceived risk of PC and their intentions to have a repeated PSA test in the future.

\section{Method}

\section{Study setting and participants}

The study was performed in 73 general practices in the Central Region of Denmark. Citizens are registered with a specific general practice, which they have to consult for medical advice, and the GP acts as gatekeeper for the rest of the healthcare system.

All patients were included from the intervention arm of the ProCaRis project ${ }^{21}$ from January 2013 to December 2013. The aim of the ProCaRis project was to identify a group of patients for whom PSA testing would have most benefit, by introducing a genetic test for lifetime risk of PC in general practice. In brief, all patients who received a PSA test at their general practice within the study period were eligible for inclusion, unless they showed one of the following exclusion criteria: aged $>80$ years; elevated PSA level $(\geq 4 \mu \mathrm{g} / \mathrm{l})$ concurrently or within the previous 2 years; known prostate or bladder disease; or a history of PC. As little control as possible was asserted over the entire inclusion process to minimise any disturbances to the normal workflow and, consequently, the reasoning behind the initial PSA test was not known to the authors; it was left solely to the GP and patient's discretion. 
In addition to having a PSA test, eligible patients had an additional $4 \mathrm{ml}$ blood sample drawn for a genetic risk assessment.

Based on genotyping of 33 risk loci and/or SNPs (adjusted for age and PC family history), the individual lifetime PC risk was calculated for each participant as previously described, ${ }^{21,23}$ and results reported as high, normal, or unknown risk. As the lifetime risk score was adjusted for age in the algorithm, no further distinction was made between younger and older participants. A high lifetime risk was considered as an absolute lifetime risk of $\geq 30 \%$, which is nearly three times higher than the average lifetime risk of $11 \%$ and thus comparable with the Danish recommendation to only offer PSA testing in men aged $>45$ years, with a family history of PC (two close relatives), and to those with a life expectancy of $>10-15$ years. ${ }^{8,24-26}$ A lifetime risk $<30 \%$ was considered 'normal'. In the rare cases, where the patient's family disposition was unknown but the total risk assessment, in theory, would change from 'normal' to 'high' in the case of a known positive family history, the total risk assessment result was reported as 'unknown'. Accordingly, after determining the risk profile (with a mean response time of 21 days after the blood sampling), one of the following messages was sent electronically to the GP:

\section{Normal lifetime risk}

'The patient belongs to a group of patients at normal lifetime risk of getting a prostate cancer diagnosis. It is not considered necessary or beneficial for the patient to have more PSA tests in the future, unless the patient develops urinary tract symptoms or one or more of his relatives develops prostate cancer.'

\section{High lifetime risk}

'The patient belongs to a group with increased risk of developing prostate cancer in the future. If the patient develops prostate cancer in the future, in most cases, the cancer will be slow growing. For early detection, the patient is encouraged to have a yearly PSA test.'

\section{Unknown lifetime risk}

'The risk for developing prostate cancer in the future cannot be estimated due to missing information for family history.'

The GP or their staff then informed the patient about the result by telephone, email, letter, or during consultation. Before the study, each practice had received written information with recommendations about follow-up PSA testing, according to current guidelines and information about the benefits and shortcomings of genetic risk assessment as a tool to support decision making about testing for PC. The researchers provided additional online information about PC screening, use of PSA tests, and genetic risk assessment for PC, as well as a project telephone hotline. ${ }^{21,27}$

\section{Measures}

PSA test results were collected from the regional clinical laboratory information system (LABKA) and included the PSA level at the time of inclusion and any PSA test(s) performed during the following 2 years after the patient's initial PSA test.

Questionnaires were sent to participants about 1 month after the genetic test result was available to the GP (and thus, approximately 2 months after initial inclusion); a reminder was sent 2 weeks later if the questionnaire had not been returned. The questionnaires contained questions about patients' awareness of their lifetime risk of PC, their perceived risk of developing PC, of their overall health, and of their intentions to have a repeat PSA test in the future (Table 1).

The genetic lifetime risk (normal, high, or unknown) results were collected directly from the laboratory at the Department of Molecular Medicine, Aarhus University Hospital, Denmark, where all genetic analyses were performed.

\section{Statistical analysis}

All statistical analyses were performed in $\mathrm{R}^{28}$ (version 3.5.1) using $\mathrm{R}$ studio (version 1.1.383). Fisher's exact test was used to test differences in distributions, while differences in means or medians were tested by Student $t$-test or Wilcoxon rank sum test, respectively. Cls were calculated from a two-sided Student $t$-test. 
Table 1 Summary of patient questionnaire used in this study. The full questionnaire participants received is available on request.

\begin{tabular}{|c|c|c|}
\hline $\begin{array}{l}\text { Question } \\
\text { label }\end{array}$ & Text & Response \\
\hline q01 & Did you have a PSA test? & $1=$ yes, $0=$ no \\
\hline q02 & Why did you take the PSA test? & \\
\hline q02_1 & I have / had urinary problems & \\
\hline q02_2 & $\begin{array}{l}\text { I got the test, as I still was at the doctor in } \\
\text { connection with another health problem }\end{array}$ & \\
\hline q02_3 & $\begin{array}{l}\text { I got it taken in conjunction with a regular } \\
\text { health check }\end{array}$ & \\
\hline q02_4 & $\begin{array}{l}\text { I got the test because I was worried that } \\
\text { I have PC }\end{array}$ & \\
\hline q02_5 & $\begin{array}{l}\text { I got it taken to be sure that I do not have } \\
\text { PC }\end{array}$ & \\
\hline q02_6 & $\begin{array}{l}\text { I had not even considered getting test } \\
\text { before my doctor recommended me }\end{array}$ & \\
\hline q02_7 & My family has advised me to take the test & \\
\hline q02_8 & $\begin{array}{l}\text { My friends / acquaintances have advised } \\
\text { me to take the test }\end{array}$ & \\
\hline q02_9 & $\begin{array}{l}\text { I have friends / acquaintances who have } \\
\text { had } P C \text { and are living with it today }\end{array}$ & \\
\hline q02_10 & $\begin{array}{l}\text { I have friends / acquaintances who have } \\
\text { died of PC }\end{array}$ & \\
\hline q02_11 & I have had PC & \\
\hline q02_12 & I have had another type of cancer & \\
\hline q02_13 & I have had an elevated PSA level & \\
\hline q02_14 & Other reason. Please specify & \\
\hline q03 & How were the results of the PSA test? & $1=$ normal, $2=$ increased, $9=$ don't know \\
\hline q04 & $\begin{array}{l}\text { How do you assess your risk of getting } \\
\text { PC, compared with other men your age? }\end{array}$ & $\begin{array}{l}1=\text { much lower, } 2=\text { lower, } 3=\text { the same, } 4=\text { higher, } 5 \\
=\text { much higher }\end{array}$ \\
\hline q05 & $\begin{array}{l}\text { How do you assess your risk of dying from } \\
\text { PC compared with other men your age? }\end{array}$ & $\begin{array}{l}1=\text { much lower, } 2=\text { lower, } 3=\text { the same, } 4=\text { higher, } 5 \\
=\text { much higher }\end{array}$ \\
\hline q06 & $\begin{array}{l}\text { Although my PSA level is normal now, I } \\
\text { am determined to ask my doctor for a } \\
\text { new PSA test over the next } 2 \text { years }\end{array}$ & $\begin{array}{l}1=\text { totally disagree, } 2=\text { disagree, } 3=\text { agree, } 4=\text { totally } \\
\text { agree, } 9=\text { don't } \mathrm{know}\end{array}$ \\
\hline q07 & How do you think your health is overall? & $\begin{array}{l}1=\text { bad, } 2=\text { less good, } 3=\text { good, } 4=\text { very good, } 5= \\
\text { excellent }\end{array}$ \\
\hline q08 & Have you had taken a genetic test? & $1=$ yes, $0=$ no \\
\hline q09 & $\begin{array}{l}\text { How was the result of your genetic } \\
\text { testing? }\end{array}$ & $1=$ normal, $2=$ increased, $9=$ don't know \\
\hline
\end{tabular}

$\mathrm{PC}=$ prostate cancer. $\mathrm{PSA}=$ prostate specific antigen.

Univariate and multivariate Cox regression analyses were performed using the survival package, ${ }^{29}$ and the endpoint was a repeat PSA test within 2 years. Patients who did not have a repeat PSA test within that timeframe were censored at 730 days (that is, 2 years). $P$ values $<0.05$ and/or differences outside $95 \% \mathrm{Cls}$ were considered significant.

To explore which factors were associated with patients' decisions to have a repeat PSA test, a multivariate Cox regression model was created using a repeat PSA test within 2 years as endpoint. Consequently, the study used genetic risk, perceived risk for PC diagnosis, perceived risk for dying of 


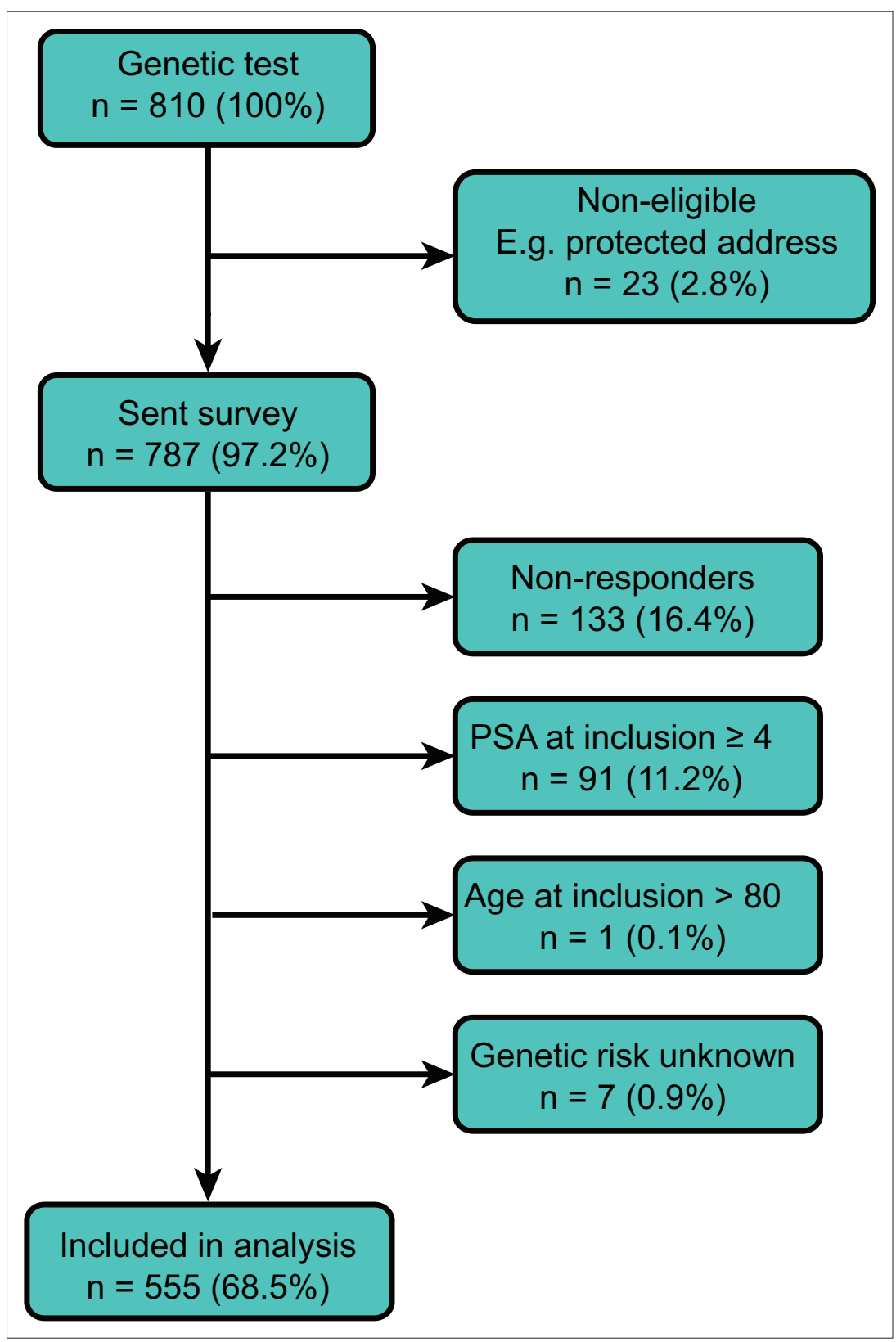

Figure 1 Flow chart of inclusion and exclusion criteria. PSA = prostate specific antigen.

$\overline{\mathrm{PC}}$, intention for a repeat PSA test, PSA level at inclusion, and awareness of having had a genetic test as possible explanatory variables.

\section{Results}

\section{Questionnaire response rate}

In total, 810 patients received a genetic test in 73 general practices. Of these, 787 patients $(97.2 \%$, Figure 1) were eligible and received the questionnaire (Table 1). After removing non-responders $(n=$ $133,16.4 \%)$, patients with PSA $\geq 4 \mu \mathrm{g} / \mathrm{l}$ at inclusion $(n=91,11.2 \%)$, patients aged 80 years $(n=1,0.1 \%)$, or unknown genetic risk ( $n=7,0.9 \%)$, a total of 555 patients $(68.5 \%)$ were included in the analysis (Table 2).

\section{Patients' understanding of their test results}

Slightly more than half of the responders $(n=306,55.1 \%)$ recalled they had a genetic test performed (q08, Table 1 and Figure 2a). The awareness of having had a genetic test was not significantly different 
Table 2 Summary of patient characteristics $(N=555)$

\begin{tabular}{|c|c|}
\hline Characteristics & $n(\%)^{a}$ \\
\hline Median age at inclusion, years (IQR) & 63.4 (56.7 to 68.9) \\
\hline Median PSA at inclusion (IQR) & $1.1(0.7$ to 2.0$)$ \\
\hline \multicolumn{2}{|l|}{ PSA levels } \\
\hline$<1 \mathrm{ng} / \mathrm{ml}$ & $213(38.4)$ \\
\hline$\geq 1 \mathrm{ng} / \mathrm{ml}$ & $342(61.6)$ \\
\hline Unknown & $0(0.0)$ \\
\hline \multicolumn{2}{|l|}{ Lifetime PC risk } \\
\hline Average risk & $482(86.8)$ \\
\hline High risk & $73(13.2)$ \\
\hline Unknown & $0(0)$ \\
\hline General wellbeing (scale 1-5), mean (SD) & $3.39(0.79)$ \\
\hline \multicolumn{2}{|l|}{ Reason to get PSA test ${ }^{\mathrm{b}}$} \\
\hline Urinary problems & $185(33.3)$ \\
\hline Saw the doctor for another health problem & $140(25.2)$ \\
\hline As part of a regular health check & $193(34.8)$ \\
\hline Worried about or ruling out having PC & $351(63.2)$ \\
\hline Not intended before doctor recommendation & $102(18.4)$ \\
\hline Family or friends or acquaintances advise & $142(25.6)$ \\
\hline Friends or acquaintances living with or died from PC & $245(44.1)$ \\
\hline Having another type of cancer & $7(1.3)$ \\
\hline Previous elevated PSA level & $8(1.4)$ \\
\hline Other reasons & $60(10.8)$ \\
\hline
\end{tabular}

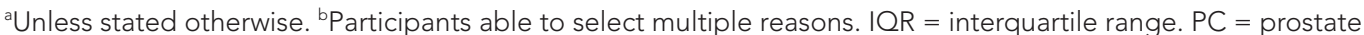
cancer. PSA = prostate-specific antigen. SD = standard deviation.

(Fisher's test, $P=0.379$ ) for patients with a high versus a normal risk test result (Figure 2a). When the patients who were aware they had received a genetic test were asked about the result of their genetic test (that is, lifetime genetic risk), patients with a normal genetic lifetime risk correctly reported their risk in $98.5 \%$ ( $n=258 / 262$ ) of cases, while a significantly smaller fraction $(75.0 \%, n=33 / 44)$ of patients with high genetic risk reported correctly (Figure $2 \mathrm{~b} ; \Delta=0.23$; $t$-test, $P<0.001 ; 95 \% \mathrm{Cl}=0.10$ to 0.37 ).

For comparison, the patients' knowledge about their PSA test result at inclusion was also analysed. For this analysis only, all responders were incorporated, including also those $(n=87)$ with a PSA level $\geq 4 \mu \mathrm{g} / \mathrm{l}$ at inclusion. Only $51.7 \%$ of patients with PSA levels $\geq 4 \mu \mathrm{g} / \mathrm{l}$ correctly reported their PSA levels as elevated (Figure 2c). In contrast, participants with normal PSA levels $(<4 \mu \mathrm{g} / \mathrm{l})$ correctly reported their PSA levels as normal in $85.6 \%$ of the cases (Figure $2 c$; change $(\Delta)=0.34$; $t$-test, $P<0.001 ; 95 \%$ $\mathrm{Cl}=0.23$ to 0.45$)$.

\section{The patients' perceived risk of PC correlated with actual genetic risk}

No significant association was found between whether the patients were aware they had received a genetic test and their perceived risk of being diagnosed with PC (Figure 3a, $P=0.68$; Fisher's exact test), or dying of PC (Figure $3 b, P=0.65$ ), nor with their intention to have a repeat PSA test within 2 years (Figure $3 c, P=0.08$ ). In contrast, a strong positive correlation was found between the patients' actual measured genetic risk and their perceived risk of getting PC (Figure $3 d, P=2.6 E$ 20; Fisher's exact test) and dying of PC (Figure 3e, $P=3.9 \mathrm{E}-9$ ), as well as their intention for a repeat PSA test (Figure $3 f, P=2.2 \mathrm{E}-5$ ). A possibility remains that this association was driven by the group of 


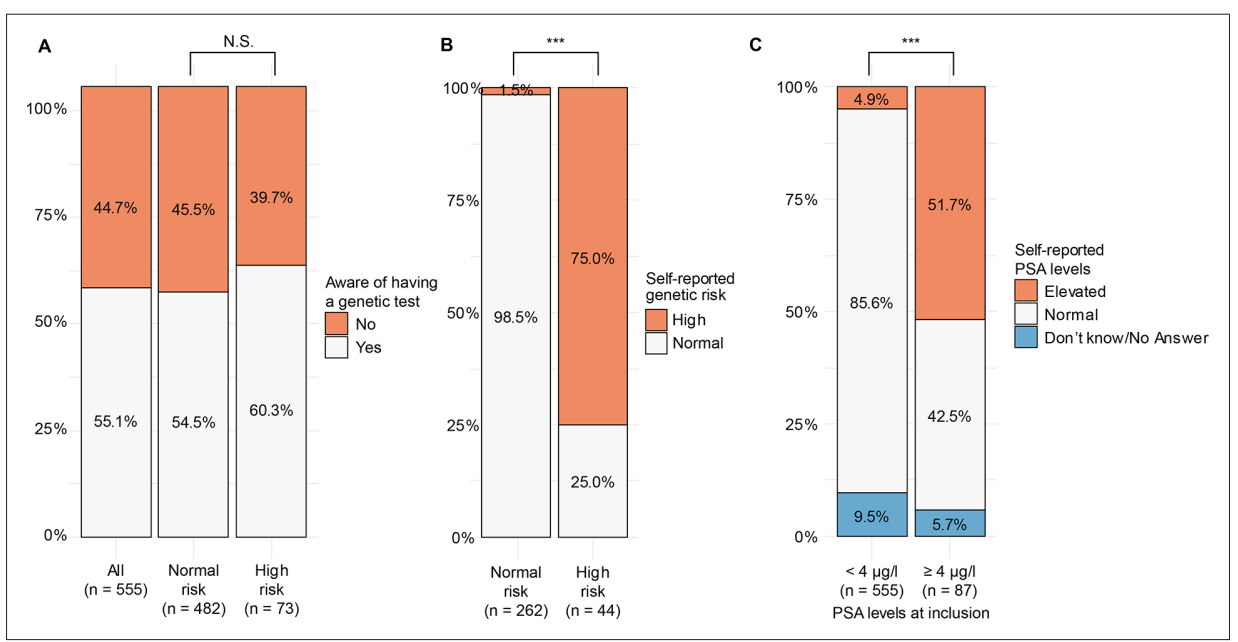

Figure 2 Self-reported outcome of tests for PC. In total, 555 patients (482 with a normal risk, 73 with a high risk) were asked if they had received a genetic test (A). Patients who were aware of the genetic test ( 262 normal risk and 44 high risk) were next asked about the result of the test (B). Out of all questionnaire responders, patients reported if their PSA levels were normal, elevated, or they did not know (or did not answer) (C). Answers were separated into bins, based on PSA level at inclusion. Fisher's exact test was used to test for difference in distribution. NS = not significant. $\mathrm{PC}=$ prostate cancer. $\mathrm{PSA}=$ prostate specific antigen. ${ }^{\star \star \star} P<0.001$.

patients who were aware they had a genetic test; however, when the patients were stratified based on awareness, the correlation between the patients' actual measured genetic risk and their perceived risks of getting PC and dying of PC remained significant regardless of awareness ( $P \leq 0.01$ in all cases). In contrast, the intention to repeat the PSA test was only significantly associated with genetic risk in the subgroup of patients who were aware that they had had a genetic test $(P=5.3 \mathrm{E}-5)$.

In a study of the same cohort by a number of the present authors, ${ }^{23}$ a strong association between the genetic risk and whether a patient had a repeat PSA test was observed. Accordingly, $83.6 \%(61$ out of 73) of patients with a high genetic risk had a repeat PSA test within 2 years, while $20.5 \%(99$ out of 487 ) of patients with a normal risk had a repeat PSA test $(\Delta=0.63$; t-test, $P<0.001 ; 95 \% \mathrm{Cl}=$ 0.54 to 0.72$)$.

\section{Regression model for repeat PSA test}

A multivariate Cox regression model revealed that a high genetic risk score was the most significant predictor of a repeated PSA test (hazard ratio $(\mathrm{HR})=5.99 ; 95 \% \mathrm{Cl}=4.09$ to $8.79, \mathrm{P}<0.001$, Table 3). In addition, the intention for a repeat PSA test was also a significant independent predictor for having a repeat PSA test $(H R=1.2 ; 95 \% \mathrm{Cl}=1.05$ to $1.37, P=0.007$, Table 3). Awareness of having the genetic test and PSA level at inclusion $(H R=1.16)$ were borderline significant predictors of a repeat PSA test $(P<0.1)$ in multivariate analysis, whereas perceived risk of getting $P C$ or dying from $P C$ were non-significant $(P \geq 0.1)$. For those who had a repeat PSA test, the median time to repeat PSA was 380 days (IQR 338 to 505 days) after the genetic risk assessment.

\section{Discussion}

\section{Summary}

This study found that almost half of the participants were unaware they had a genetic assessment of their lifetime risk for PC. Of those who were aware, up to $25 \%$ did not correctly report their risk; however, the results showed that the actual genetic risk, and not an awareness of having the genetic test correlated with the patients' perceived risk of PC, their intention to repeat their PSA test, and whether they then had a repeat PSA test. Together, this appears to indicate that patients followed the advice given by their GP (that is, to repeat the PSA test or not), despite not necessarily comprehending the test result. Alternatively, the GPs may not have found it essential to convey the details of the test result and simply gave patients the recommendations. 


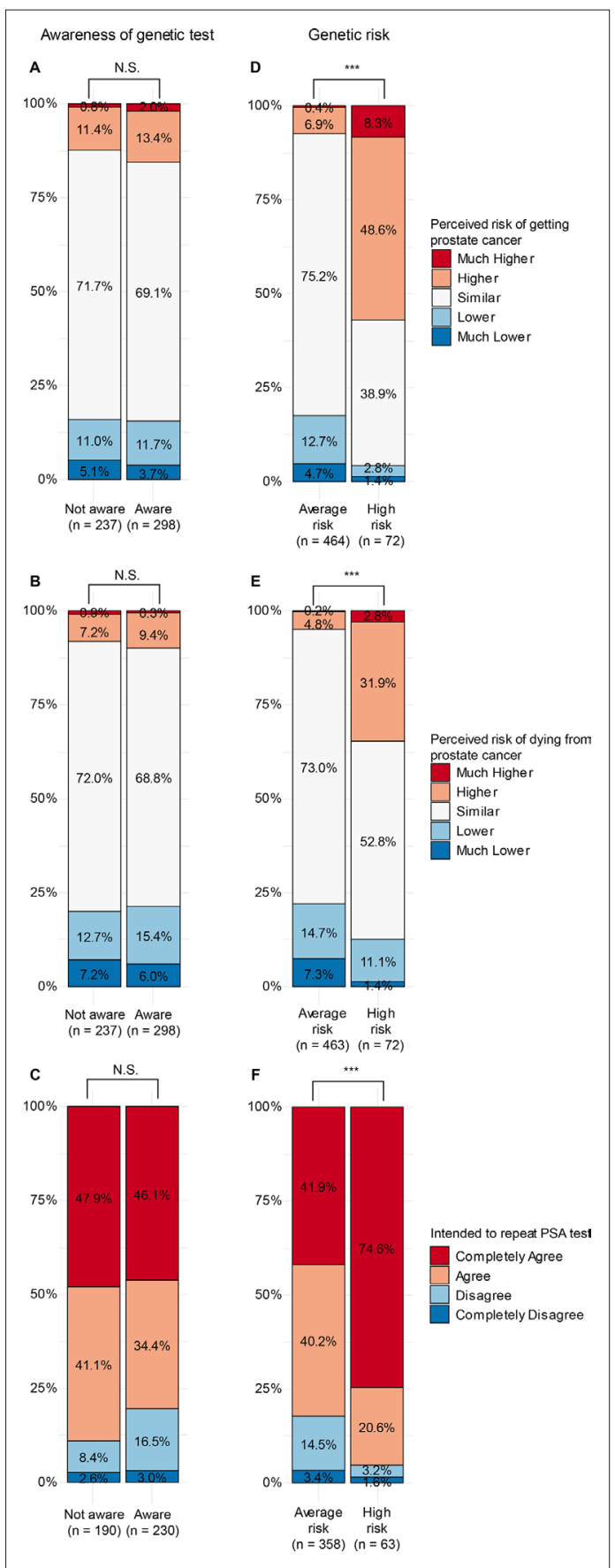

Figure 3 Self-reported perceived risk of getting a PC diagnosis, dying of $\mathrm{PC}$, or intention of a repeat PSA test. Patients were asked about their perceived risk of getting $P C$ and/or dying from $P C$ on a scale of $1-5$, as well as their intent to have a repeat PSA test within 2 years on a scale of $1-4$. The perceived risks and intention were plotted against awareness of having the genetic test (A-C), or the actual test result of measured genetic risk (D-F). Fisher's exact test was used to test for difference in distribution. PC = prostate cancer. PSA $=$ prostate specific antigen. NS = not significant. $\star \star \star * P<0.001$.

\section{Strengths and limitations}

To the best of the authors' knowledge, this is the first prospective study using a genetic risk test to promote targeted PSA screening of high-risk individuals in general practice, coupled with assessment of patient behaviour. A strength of this study is the availability of data from registries in addition to the questionnaires. This enhanced the validity of the data, especially because many patients were not aware of the genetic test result. Furthermore, using registries made it possible to collect data at different time points (the genetic test and data on any follow-up PSA test 2 years later).

Since the inception of this study, more PCrelated SNPs have been identified, ${ }^{12-14}$ making risk assessment potentially more precise. However, as the endpoint in the present study was patient behaviour and not PC diagnosis, the accuracy of the risk assessment is not expected to influence the results presented here.

The risk of performance bias was low as the intervention comprised only paper-based information and clinical advice, and no education or training of GPs was required. However, this will often be the case when new tests are introduced in health services.

\section{Comparison with existing literature}

The low awareness of participant's genetic test result is consistent with a previous study where patients had poor recall of risk figures given to them in genetic counselling sessions. ${ }^{30}$ This raises questions over whether patients actually understand the meaning and purpose of the test. A potential reason for this low awareness could be that the decision to test was not based on patients' requests; the tests were offered by their GP. The authors speculate that patients might have taken the test simply because more testing is felt to be 'better'. ${ }^{22,31}$

The strong direct effect of lifetime risk for $\mathrm{PC}$ on follow-up PSA tests, despite the patients' limited awareness of having the genetic test, suggests that GPs play an important role in the decision about follow-up PSA testing. While it is not known how (and whether) the GPs conveyed the purpose of the test and the result to the patients, patient behaviour and risk perception was changed following the genetic risk assessment process. This likely indicates that patients largely followed their GPs' recommendations. This is even more evident for patients who were not aware of their normal (that is, non-elevated) 
Table 3 Cox regression analysis for repeat PSA test ( $N=555,160$ with repeat PSA test). Uni- and multi-variate Cox regression, using genetic risk score, awareness of having a genetic test, PSA level at inclusion, perceived risk of PC, perceived risk of dying from PC, and intention for a repeat PSA were investigated as potential explanatory variables for actually having a repeat PSA test within 2 years.

\begin{tabular}{|c|c|c|c|c|c|c|}
\hline \multirow[b]{2}{*}{ Variable } & \multirow[b]{2}{*}{ Characteristics } & \multicolumn{3}{|c|}{ Univariate } & \multicolumn{2}{|c|}{ Multivariate } \\
\hline & & $\mathrm{HR}(95 \% \mathrm{Cl})$ & $P$ value & C-index ${ }^{a}$ & HR (95\% Cl) & $P$ value \\
\hline Genetic risk & Normal versus high & $\begin{array}{c}8.11 \\
\text { (5.83 to } 11.29)\end{array}$ & $<0.001$ & 0.66 & $\begin{array}{c}5.99 \\
(4.09 \text { to } 8.79)\end{array}$ & $<0.001$ \\
\hline $\begin{array}{l}\text { Awareness of having } \\
\text { a genetic test }\end{array}$ & No versus yes & $\begin{array}{c}1.23 \\
(0.90 \text { to } 1.69)\end{array}$ & 0.193 & 0.53 & $\begin{array}{c}1.32 \\
\text { (0.95 to } 1.83)\end{array}$ & 0.099 \\
\hline PSA at inclusion & Continuous & $\begin{array}{c}1.24 \\
(1.05 \text { to } 1.46)\end{array}$ & 0.0097 & 0.56 & $\begin{array}{c}1.16 \\
\text { (0.98 to } 1.38)\end{array}$ & 0.083 \\
\hline Perceived risk for PC & $1-5$ & $\begin{array}{c}2.13 \\
\text { (1.68 to } 2.71)\end{array}$ & $<0.001$ & 0.62 & $\begin{array}{c}1.2 \\
\text { (0.83 to } 1.74)\end{array}$ & 0.331 \\
\hline $\begin{array}{l}\text { Perceived risk for } \\
\text { dying of PC }\end{array}$ & $1-5$ & $\begin{array}{c}1.77 \\
\text { (1.38 to } 2.28)\end{array}$ & $<0.001$ & 0.59 & $\begin{array}{c}1.11 \\
\text { (0.79 to } 1.57)\end{array}$ & 0.553 \\
\hline $\begin{array}{l}\text { Intention for repeat } \\
\text { PSA test }\end{array}$ & $1-4$ & $\begin{array}{c}1.35 \\
(1.18 \text { to } 1.54)\end{array}$ & $<0.001$ & 0.62 & $\begin{array}{c}1.2 \\
(1.05 \text { to } 1.37)\end{array}$ & 0.007 \\
\hline
\end{tabular}

${ }^{a} \mathrm{C}$-index, Harrell's concordance index. HR = hazard ratio. PC = prostate cancer. PSA = prostate specific antigen.

genetic risk, but still had fewer PSA tests within 2 years. ${ }^{23}$ The relatively smaller indirect effect through perceived risk is consistent with earlier studies that found limited effects of long-term genetic testing on perceived risk. ${ }^{32}$

\section{Implications for research and practice}

The simplicity of the intervention, combined with the differences between patients with normal and high lifetime risk at follow-up PSA testing, makes this intervention a candidate for broader implementation to enhance appropriate PSA testing. However, before doing this, further research about the potential effects of this genetic test is required. First, the low awareness among patients receiving a genetic test provides a challenge for broader implementation of this test. It is possible that the GP did not use the wording 'genetic test' per se, but rather a lifetime risk test and, as such, it is not expected from the patients to know they had a genetic test. However, it is believed that the implications of the low awareness of a genetic test would have little impact on the decision-making process. Rather, a tangible recommendation is provided (that is, have an annual PSA test, or no benefit from screening). The effect of this recommendation can be seen in the data.

Further studies are required to determine how to communicate the test results effectively to patients, and to evaluate whether the genetic test could be integrated with a decision aid to support informed decision-making between men and their GP about appropriate PSA testing. Second, this report did not focus on the effect of the intervention on overall PSA test usage, as this has already been addressed elsewhere. ${ }^{23}$ Future studies should assess both the effects of communication strategies and offering a genetic test for lifetime PC risk on the number of PC diagnoses. Ideally, such future studies should include an optimised genetic test that includes all currently known PC risk variants.

Despite limited understanding of test results, offering a genetic test to assess the lifetime risk of PC altered the behaviour of patients about having a repeat PSA test within 2 years. Such an intervention could, in the future, form the basis for actively supporting informed decision-making between men and their GP in routine practice.

Funding

This work was supported by grants from The Danish Strategic Research Council (now Innovation Fund Denmark, reference number: 10-092796), The Danish Cancer Society (reference number: R130A8313-15-S38), and The Velux Foundation (reference number: 11307). 


\section{Ethical approval}

This study was conducted according to the Helsinki Declaration principles and was notified to the Danish Data Protection Agency (Journal no. 2011-41-6904). This study has obtained permission from The Danish National Committee on Health Research Ethics (Journal no. 1-10-72-43-12) and was registered at the ClinicalTrials.gov (reference number: NCT01739062). Patients received printed information about the study from the GP and could withdraw from the study at any time, and have their blood sample and data destroyed.

\section{Provenance}

Freely submitted; externally peer reviewed.

\section{Acknowledgements}

The authors would like to thank Dr. Jan Koutsenruiter for helpful discussions in the initial phase of this study; and Margaret Gellet, Gitte Nielsen, Karen Bihl, and Anne Slotsdal for excellent technical assistance. The authors are very grateful to all the GPs and patients who contributed to and participated in this study.

\section{References}

1. Boyle P, Ferlay J. Cancer incidence and mortality in Europe, 2004. Ann Oncol 2005; 16(3): 481-488. DOI: https:// doi.org/10.1093/annonc/mdi098

2. Damber J-E, Aus G. Prostate cancer. The Lancet 2008; 371(9625): 1710-1721. DOI: https://doi.org/10.1016/S01406736(08)60729-1

3. Parkin DM, Bray F, Ferlay J, Pisani P. Global cancer statistics, 2002. CA Cancer J Clin 2005; 55(2): 74-108. DOI: https://doi.org/10.3322/canjclin.55.2.74

4. Parkin DM, Bray F, Ferlay J, Pisani P. Estimating the world cancer burden: Globocan 2000. Int J Cancer 2001 ; 94(2): 153-156. DOI: https://doi.org/10.1002/ijc.1440

5. Schröder FH, Hugosson J, Roobol MJ, et al. Screening and prostate-cancer mortality in a randomized European study. N Engl J Med 2009; 360(13): 1320-1328. DOI: https://doi.org/10.1056/NEJMoa0810084

6. Schröder FH, Hugosson J, Roobol MJ, et al. Screening and prostate cancer mortality: results of the European randomised study of screening for prostate cancer (ERSPC) at 13 years of follow-up. The Lancet 2014; 384(9959): 2027-2035. DOI: https://doi.org/10.1016/S0140-6736(14)60525-0

7. Grossman DC, Curry SJ, Owens DK, et al. US Preventive Services Task force. screening for prostate cancer: US Preventive Services Task Force recommendation statement. JAMA 2018; 319(18): 1901-1913. DOI: https://doi.org/ 10.1001/jama.2018.3710

8. DaProCa (Danish Prostate Cancer Group). [Screening and early detection of prostate cancer] Screening \& tidlig detektion af prostatacancer (in Danish). 2018; http://ducg.dk/fileadmin/www.ducg.dk/Prostatacancer/Kl. retningslinjer/2019/5 1_PSA og_screening.pdf (accessed 24 Mar 2020).

9. Hodgson F, Obertová Z, Brown C, Lawrenson R. PSA testing in general practice. J Prim Health Care 2012; 4(3): 199-204. DOI: https://doi.org/10.1071/HC12199

10. Neal DE. PSA testing for prostate cancer improves survival — but can we do better? Lancet Oncol 2010; 11(8): 702-703. DOI: https://doi.org/10.1016/S1470-2045(10)70152-2

11. Eeles RA, Olama AAA, Benlloch $\mathrm{S}$, et al. Identification of 23 new prostate cancer susceptibility loci using the iCOGS custom genotyping array. Nat Genet 2013; 45(4): 385-391. DOI: https://doi.org/10.1038/ng.2560

12. Dadaev T, Saunders EJ, Newcombe PJ, et al. Fine-mapping of prostate cancer susceptibility loci in a large metaanalysis identifies candidate causal variants. Nat Commun 2018; 9(1): 2256. DOI: https://doi.org/10.1038/s41467018-04109-8

13. Matejcic M, Saunders EJ, Dadaev T, et al. Germline variation at $8 \mathrm{q} 24$ and prostate cancer risk in men of European ancestry. Nat Commun 2018; 9(1): 4616. DOI: https://doi.org/10.1038/s41467-018-06863-1

14. Schumacher FR, Al Olama AA, Berndt SI, et al. Association analyses of more than 140,000 men identify 63 new prostate cancer susceptibility loci. Nat Genet 2018; 50(7): 928-936. DOI: https://doi.org/10.1038/s41588-0180142-8

15. Aly $\mathrm{M}$, Wiklund $\mathrm{F}, \mathrm{Xu} \mathrm{J}$, et al. Polygenic risk score improves prostate cancer risk prediction: results from the Stockholm-1 cohort study. Eur Urol 2011; 60(1): 21-28. DOI: https://doi.org/10.1016/j.eururo.2011.01.017

16. Grönberg $\mathrm{H}$, Adolfsson J, Aly $M$, et al. Prostate cancer screening in men aged 50-69 years (STHLM3): a prospective population-based diagnostic study. Lancet Oncol 2015; 16(16): 1667-1676. DOI: https://doi.org/10.1016/S14702045(15)00361-7

17. Jin G, Lu L, Cooney KA, et al. Validation of prostate cancer risk-related loci identified from genome-wide association studies using family-based association analysis: evidence from the International Consortium for Prostate Cancer Genetics (ICPCG). Hum Genet 2012; 131(7): 1095-1103. DOI: https://doi.org/10.1007/s00439-011-1136-0

18. Roobol MJ, Carlsson SV. Risk stratification in prostate cancer screening. Nat Rev Urol 2013; 10(1): 38-48. DOI: https://doi.org/10.1038/nrurol.2012.225 
19. Zhu X, Albertsen PC, Andriole GL, et al. Risk-based prostate cancer screening. Eur Urol 2012; 61(4): 652-661. DOI: https://doi.org/10.1016/j.eururo.2011.11.029

20. Joseph-Williams N, Elwyn G, Edwards A. Knowledge is not power for patients: a systematic review and thematic synthesis of patient-reported barriers and facilitators to shared decision making. Patient Educ Couns 2014; 94(3): 291-309. DOI: https://doi.org/10.1016/j.pec.2013.10.031

21. Kirkegaard $P$, Vedsted $P$, Edwards A, et al. A cluster-randomised, parallel group, controlled intervention study of genetic prostate cancer risk assessment and use of PSA tests in general practice — the ProCaRis study: study protocol. BMJ Open 2013; 3(3): e002452. DOI: https://doi.org/10.1136/bmjopen-2012-002452

22. Kirkegaard P, Edwards A, Nielsen TLO, et al. Perceptions about screening for prostate cancer using genetic lifetime risk assessment: a qualitative study. BMC Fam Pract 2018; 19(1): 32. DOI: https://doi.org/10.1186/s12875-0180717-6

23. Fredsøe J, Koetsenruyter J, Vedsted P, et al. The effect of assessing genetic risk of prostate cancer on the use of PSA tests in primary care: a cluster randomized controlled trial. PLoS Med 2020; 17(2): e1003033. DOI: https://doi. org/10.1371/journal.pmed.1003033

24. Albright F, Stephenson RA, Agarwal N, et al. Prostate cancer risk prediction based on complete prostate cancer family history. Prostate 2015; 75(4): 390-398. DOI: https://doi.org/10.1002/pros.22925

25. Hansen BL, Lose G, McNair SB. [Assessment and treatment of lower urinary tract symptoms in men and women] Udredning OG behandling AF nedre urinvejssymptomer HOS mænd OG kvinder (in Danish). 1st edn. Copenhagen: Dansk Selskab for Almen Medicin; 2009.

26. American Cancer Society. Key statistics for prostate cancer. 2019; https://www.cancer.org/cancer/prostate-cancer/ about/key-statistics.html (accessed 25 Mar 2020).

27. Center for Forskning i Cancerdiagnostik i Praksis (CaP). [ProCaRis II - Genetic risk assessment for prostate cancer] ProCaRis II - Genetisk risikovurdering for prostatakræft (in Danish). 2019; http://cap.au.dk/procaris-ii/ (accessed 25 Mar 2020).

28. R Core Team. R: a language and environment for statistical computing. Vienna: R Foundation for Statistical Computing; 2017.

29. Therneau TM, Grambsch PM. Modeling survival data: extending the COX model. New York, NY: Springer; 2000.

30. Sivell S, Elwyn G, Gaff CL, et al. How risk is perceived, constructed and interpreted by clients in clinical genetics, and the effects on decision making: systematic review. J Genet Couns 2008; 17(1): 30-63. DOI: https://doi.org/10. 1007/s10897-007-9132-1

31. Chapple A, Ziebland S, Hewitson P, McPherson A. Why men in the United Kingdom still want the prostate specific antigen test. Qual Health Res 2008; 18(1): 56-64. DOI: https://doi.org/10.1177/1049732307309000

32. Butow PN, Lobb EA, Meiser B, et al. Psychological outcomes and risk perception after genetic testing and counselling in breast cancer: a systematic review. Med J Aust 2003; 178(2): 77-81. DOI: https://doi.org/10.5694/j. 1326-5377.2003.tb05069.x 